\title{
Sea cucumbers in a pickle: the economic geography of the serial exploitation of sea cucumbers
}

\author{
$\underline{\text { Kathryn Rawson }}^{1}$ and $\underline{\text { Porter Hoagland }}^{2}$
}

\begin{abstract}
Serial exploitation comprises a pattern of the human exploitation of wild harvest fisheries, where previously untapped species or locations come under exploitation over both space and time. Unless managed sustainably, serial exploitation can lead to serial depletion of local fisheries, thereby adversely affecting local ecosystems, economies, and communities. Serial depletion is an archetypal problem of the Anthropocene, as its occurrence depends on trade linkages between consumers in one location and suppliers from sometimes geographically very distant fisheries. Invertebrates, especially echinoderms such as sea cucumbers, are subject to serial exploitation that is occurring now on a global scale. We found that the serial depletion of sea cucumbers was consistent with variability in the global mean price for sea cucumbers. When local fisheries are depleted, price tends to rise; a rising price signals previously unexploited fisheries to begin supplying the market. This cycle repeats itself, spreading from the regional to the global scale. Improved understanding of what drives serial exploitation may allow for more successful management of sea cucumber fisheries in the future.
\end{abstract}

Key Words: Anthropocene; bêche-de-mer; echinoderms; global markets; serial exploitation

\section{INTRODUCTION}

In the Anthropocene, many narratives surrounding global fisheries have been those of decline, depletion, and sometimes despair, prompting investigations into human patterns of the use of marine resources (FAO 2016). Global fisheries in general have exhibited patterns of expanding fishing pressure and overfishing since the 1950s, yet many signs of depletion within specific taxa or in certain locations have been masked by global and regional reported trends (Pauly et al. 2002, Srinivasan et al. 2012). Examining the exploitation patterns of particular fisheries and understanding what drives those patterns may lead to better informed future fisheries conservation and management.

Sea cucumbers are marine invertebrates in the phylum Echinodermata, class Holothuroidea that are subject to a global pattern of serial exploitation (Anderson et al. 2010, 2011, Eriksson and Byrne 2015). Demand for sea cucumbers, which are used principally as luxury food items and for traditional medicine (in the form of "bêche-de-mer"), arises primarily in Asian markets (Bruckner et al. 2003, Bordbar et al. 2011, Fabinyi 2011). In fact, Hong Kong is the primary importer of sea cucumbers, often handling more than $50 \%$ of global sea cucumber imports, much of which are subsequently re-exported to markets in surrounding countries (To and Shea 2012, Conand et al. 2014).

Serial exploitation is a pattern of the progressive human exploitation of natural resources, such as wild-harvest fisheries, where previously untapped species or locations come under exploitation over both space and time. Exemplifying a type of conservation problem unique to the Anthropocene, the serial exploitation of sea cucumbers is just one component of the rapid expansion of invertebrate fisheries around the world in recent decades (Anderson et al. 2010, 2011). Other invertebrate fisheries that are experiencing serial exploitation or depletion include the abalone fishery along the coast of California (Karpov et al. 2000), crustacean resources in the Gulf of Alaska (Armstrong et al. 1998), and fisheries for sea urchins (Berkes et al. 2006).

Most sea cucumber fisheries are data-poor. Lack of knowledge about sea cucumber life histories and the biological parameters affecting growth and ecological interactions presents a significant challenge to effective local management (Bruckner et al. 2003, Toral-Granda et al. 2008). These fisheries can be very important to developing communities, however, and the extirpation of sea cucumbers from some areas could have very negative local socioeconomic and environmental impacts (Bruckner et al. 2003, Purcell et al. 2016a,b).

Bio-economics is a modeling approach that incorporates biological and economic functions and parameters into a joint system of analysis. Employing this kind of methodology could provide insights into the effects of management decisions on the larger global pattern of the serial exploitation of sea cucumbers. The objectives of this study were first to test whether ex-vessel price was a significant driver of the global serial exploitation of sea cucumbers, and second to explore how local management practices potentially could mitigate this global phenomenon.

\section{METHODS}

\section{Theoretical model}

To show how prices can drive the serial exploitation of natural resources like sea cucumbers, we considered a theoretical situation (Fig. 1A) where two origin markets supply —in sequence - a single large destination market. Backward-bending supply curves were used to characterize the behavior of the local production of sea cucumbers, thus reflecting general biological population growth relationships of local sea cucumber stocks. These supply curves are reflective of the qualitative consequences in unmanaged local fisheries in which the seafood product becomes increasingly costly - but also increasingly more difficult — to supply as the fishery is overexploited and stocks become depleted.

Begin with the situation where the supply of sea cucumbers from any fisheries geographically near a Destination Market has been depleted (Fig. 1B). Where demand for sea cucumbers in the Destination Market remains high, the price for sea cucumbers also remains relatively high $\left(P_{1}^{\mathrm{a}}\right)$. This price provides an incentive for fishers in a more geographically distant Origin Market 1 to begin harvesting and exporting their sea cucumber yields to the Destination Market. These exports will cause the price of sea cucumbers in the Destination Market to shift down slightly to 
Fig. 1. A: Timeline of simplified process of serial exploitation. B: Simple theoretical model of sea cucumber serial exploitation showing how high prices in the destination market provide incentive for additional countries to begin exploiting and exporting sea cucumber products, thus driving the global pattern of serial exploitation.

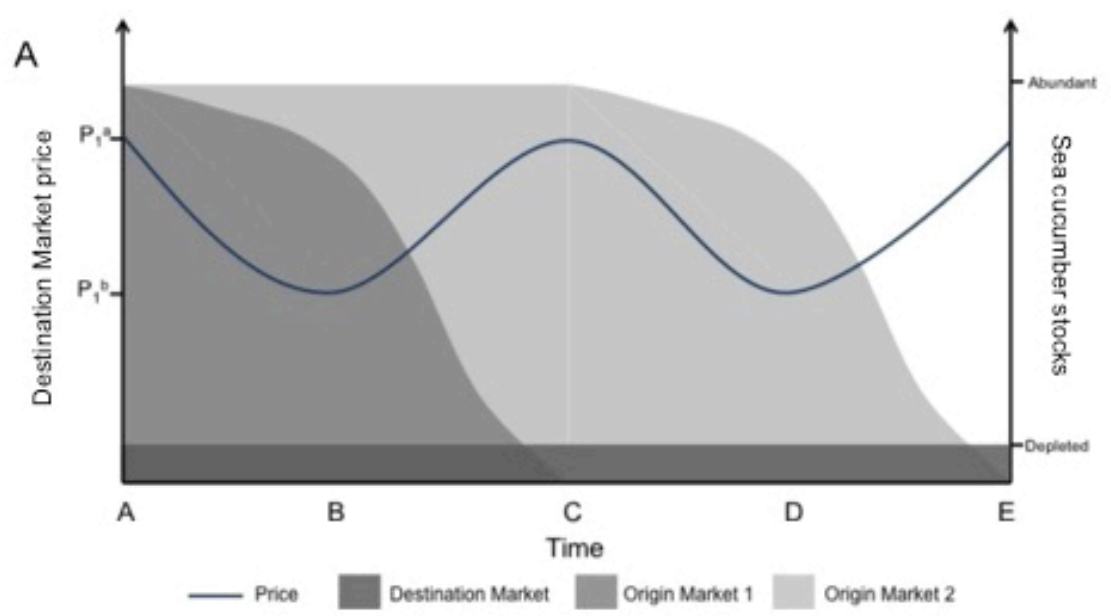

\section{$\underline{\text { Time A }}$}

- Sea cucumber stocks near the Destination Market are depleted.

- Demand remains high $\left(\mathrm{D}_{1}\right)$.

- High price for sea cucumber products in Destination Market $\left(\mathrm{P}_{1}{ }^{\mathrm{a}}\right)$.

\section{Time B}

- High price incentivizes harvest of sea cucumbers beyond local demand $\left(D_{2}\right)$ in Origin Market 1 for export to Destination Market.

- Influx of sea cucumber products in the Destination Market shifts price down slightly to $P_{1}$.

\section{$\underline{\text { Time D }}$}

- High price incentivizes harvest in Origin Market 2 beyond local demand $\left(D_{3}\right)$.

- Influx of sea cucumber products shifts price in Destination Market back down to $\mathrm{P}_{1}{ }^{\mathrm{b}}$.

This pattern of serial exploitation could continue as demand remains high enough to command elevated prices and there are still new sources available.

\section{$\underline{\text { Time C }}$}

- Sea cucumber stocks in Origin Market 1 become depleted.

- Price in Destination Market shifts back up to $P_{1}{ }^{a}$.

B Destination Marke
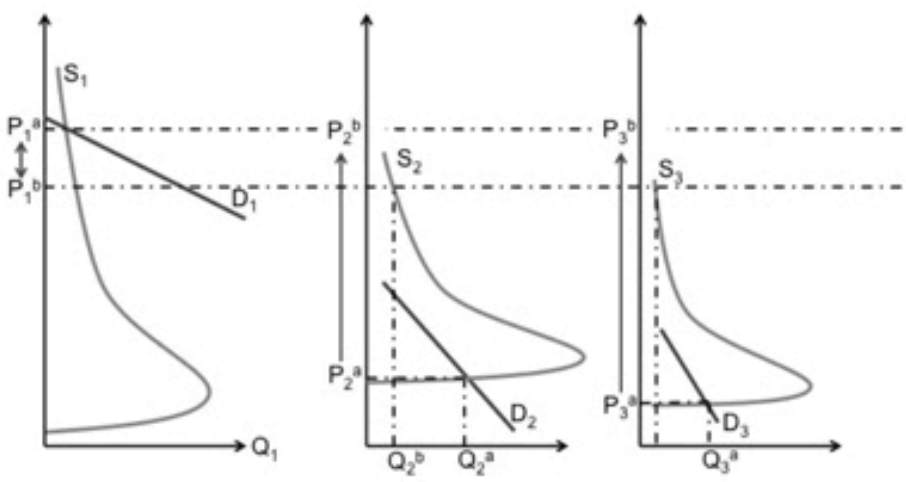
$P_{1}{ }^{\mathrm{b}}$. The sea cucumber stocks in Origin Market 1 eventually also experience depletion, however, leading to limits on that fishery's ability to supply the Destination Market $\left(Q_{2}^{\mathrm{b}}\right)$. This depletion causes the international price to shift back up to $P_{1}{ }^{a}$. If demand continues to remain high in the Destination Market, now unable to be met by the depleted resources of Origin Market 1, then Origin Market 2 is incentivized to begin harvesting and exporting its sea cucumbers. Thus, the same process of initial exploitation followed by depletion is repeated in another geographically more distant fishery.

This process of dynamic price adjustments and sequential overexploitation of wild sea cucumber stocks in one fishery after another comprises the phenomenon of serial depletion. Importantly, if a particular fishery decides to adopt conservation and management measures to curb local overexploitation, its restrictions on supply to the Destination Market would only perpetuate the price signals from that market, thereby encouraging yet other fisheries to enter and begin exporting. Note that a careful management of a local fishery that leads to the realization of resource rents, such as through a system of taxes or transferable quotas or property right allocations in that local fishery, still could be economically very beneficial to the local fishery's managers (e.g., the government or a cooperative) or to its regulated participants.

\section{Data sources}

We used sea cucumber catch and value data for global sea cucumber fisheries from the Sea Around Us Project (SAUP) (Pauly and Zeller 2015). The taxonomic groups available in the SAUP query platform that we considered were Holothuria atra (lollyfish), Holothira edulis (pinkfish), Holothuriidae (fleshy sea cucumbers), and Holothuroidea (sea cucumbers). Additionally, we obtained records of catch and value for all exploited sea cucumbers combined that were fished in the U.S. west coast states, Washington and California, from the Pacific Fisheries Information Network (PacFIN 2017), and for the state of Maine from the Maine Department of Natural Resources (DMR 2017). All catch types (i.e., reported and unreported) and end uses were combined so that a single data point for each country/area per year was considered in our analysis. All catch data were reported in metric tons (MT). Value of catch data was reported as ex-vessel price, or the price fetched by a fisheries product at its first point of sale. The SAUP value data were reported in 2010 U.S. dollars; value data from other sources were converted to 2010 U.S. dollars using the U.S. Consumer Price Index (BLS 2017). Our investigation considered only fisheries that reported catches of more than 250 MT for more than one year, following inclusion criteria adopted by Anderson et al. (2010).

The SAUP data provided an advantage over raw landings data from sources such as the UN Food and Agriculture Organization because they included both officially reported catch and reconstructed estimates of unreported catch, thus giving a plausibly more accurate estimate of the true amount of sea cucumber resource exploitation (Pauly and Zeller 2015). The data we obtained from the Pacific Fisheries Information Network and the Maine Department of Natural Resources did not include estimates of unreported catch, and so provided a less detailed estimate of actual sea cucumber exploitation for those areas.
To visualize the extent and progression of the serial exploitation of sea cucumbers, we used data on fishery start dates from Anderson et al. (2010) and SAUP (Pauly and Zeller 2015). Start dates from the Anderson et al. (2010) source were adjusted to be at the point where each fishery reached $10 \%$ of its peak catch, but the start dates for additional countries from the SAUP source were unadjusted, referencing the first year in which catch was reported from that country/area. Start dates were then mapped in RStudio using Natural Earth vector map data (https://www. naturalearthdata.com/) and the ggmap package of Kahle and Wickham (2013).

\section{Measures of serial exploitation}

We developed two measures of serial exploitation. First, we considered simply the number of countries and areas that reported sea cucumber catch in a given year. With this measure, smaller numbers would indicate relatively less serial exploitation, while larger numbers would indicate relatively more. The second measure incorporated a spatial component. We considered the distance of fisheries participating in the global sea cucumber fishery from the most influential import market, Hong Kong, by calculating the mean great circle distance to Hong Kong from the most populous city in each country or area that reported catch in a given year. This second measure of serial exploitation was inspired by the methods of Anderson et al. (2010).

Our measures of serial exploitation are rudimentary and reflect neither the true complexities involved with harvesting, processing, and transporting sea cucumbers nor the interaction between local customs and global trends. The first measure of serial exploitation is subject to error due to the data-poor nature of many sea cucumber fisheries, and to differences in fisheries landings reporting around the world. Additionally, it does not incorporate countries/areas that may have once contributed to the global sea cucumber supply but whose resources are now recovered. The second measure is also subject to error because it is quite possible that the most populous city in each area is not a city through which most sea cucumber resources pass. These measures also ignore other dimensions of serial exploitation such as size and species. Even with these drawbacks, we considered these data to comprise the best available informative measures of the serial depletion phenomenon.

\section{Model construction}

Our models comprised linear or quadratic relationships between the measures of serial exploitation and different combinations of drivers (predictor variables). The drivers we chose to examine were (1) the mean value per metric ton (VPT) of sea cucumbers for each year of the global sea cucumber fishery, (2) the VPT of sea cucumbers for the previous year, and (3) a time trend comprising years (Year) to model unobserved factors affecting measures of serial depletion. We developed a total of eight regression models (Table 1) to test these relationships. Quadratic transformations of current VPT and VPT lagged one year were included to improve model fit and test for possible diminishing returns to VPT.

\section{RESULTS}

Mapping the start dates of sea cucumber fisheries with temporal isoclines can be an effective means of visualizing the progression of the global serial exploitation of sea cucumbers over space and time (Fig. 2) (cf. Berkes et al. 2006 for sea urchins, another echinoderm exhibiting serial depletion). 
Table 1. Predictor variables and measures of serial exploitation that were selected to be included in each model. $\mathrm{X}$ indicates that a certain term is included in a model (VPT: value per metric ton).

\begin{tabular}{|c|c|c|c|c|c|c|}
\hline \multirow[b]{2}{*}{ Model } & \multirow[b]{2}{*}{ Serial exploitation measure } & \multicolumn{5}{|c|}{ Predictor variables } \\
\hline & & Present year VPT & Present year $\mathrm{VPT}^{2}$ & Previous year VPT & Previous year VPT $^{2}$ & Year \\
\hline 1a & Number of countries or areas & $\mathrm{X}$ & $\mathrm{X}$ & & & \\
\hline $1 \mathrm{~b}$ & Mean great circle distance & $\mathrm{X}$ & $\mathrm{X}$ & & & \\
\hline $2 \mathrm{a}$ & Number of countries or areas & & & $\mathrm{X}$ & $\mathrm{X}$ & \\
\hline $2 \mathrm{~b}$ & Mean great circle distance & & & $\mathrm{X}$ & $\mathrm{X}$ & \\
\hline $3 \mathrm{a}$ & Number of countries or areas & $\mathrm{X}$ & $\mathrm{X}$ & & & $\mathrm{X}$ \\
\hline $3 b$ & Mean great circle distance & $\mathrm{X}$ & $\mathrm{X}$ & & & $\mathrm{X}$ \\
\hline $4 a$ & Number of countries or areas & & & $\mathrm{X}$ & $\mathrm{X}$ & $\mathrm{X}$ \\
\hline $4 b$ & Mean great circle distance & & & $\mathrm{X}$ & $\mathrm{X}$ & $\mathrm{X}$ \\
\hline
\end{tabular}

Fig. 2. Geography of global sea cucumber exploitation. Temporal isoclines show fisheries expanding as those more proximate to Asian markets fail to meet demand. Colored lines represent the global distribution of sea cucumber fisheries within a given decade; specific starting years of some fisheries are labeled over the general location of the largest city (by population) within the participating country (cf. Berkes et al. 2006). Data obtained from Anderson et al. 2010 and Pauly and Zeller's (2015) SAUP database. Map created using Kahle and Wickham's (2013) ggmap package for RStudio.

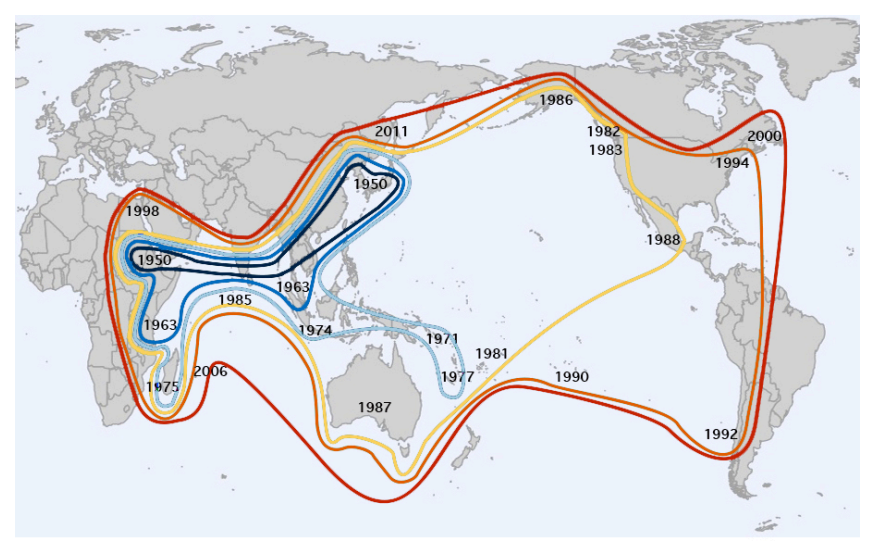

We found that variability in observed serial exploitation was explained by our measure of the price (VPT) of sea cucumbers. When price increased, our measures of serial exploitation also increased. Although not all predictors were significant in each model, all models had highly significant $F$ statistics (Table 2). Models that included a year term to control for time effects explained significantly more variability in the measures of serial exploitation than those that did not (Models 1a versus 3a: $F=$ 456.63, $p<<0.01$; 1 b versus $3 \mathrm{~b}: F=269.67, p<<0.01$; 2 a versus 4a: $F=417.14, p<<0.01 ; 2$ b versus $4 \mathrm{~b}: F=288.3, p<<0.01)$. Both VPT and one-year lagged VPT explained similar amounts of variation in serial exploitation (Table 2). Model 4a is preferred because it allows for the most intuitive interpretation; in this model, the entry of new sea cucumber fisheries is explained by price increases in the previous year (Fig. 3).
Fig. 3. Visual representation of model 4a. Year (the general time variable) is incorporated through use of color to fill dots representing each year.

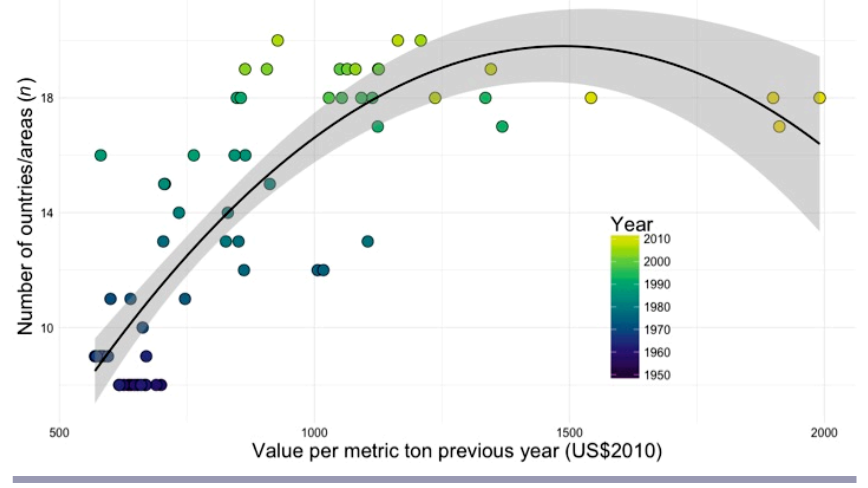

\section{DISCUSSION}

Characterizing the economic geography of serial exploitation may allow for a more complete understanding of patterns of exploitation for sea cucumbers by providing insights into specific drivers of the phenomenon. The data revealed increasing trends in both serial exploitation measures: (1) the number of countries/ areas in the global fishery in a year, and (2) the mean distance from Hong Kong of sea cucumber fisheries participating in a year (Fig. 4). After accounting for these factors, the models explained observed variation in the entry of fisheries into the world market as a function of increasing sea cucumber price.

Notably, the highest levels of value did not correspond with the largest measures of serial exploitation (Fig. 3). A quadratic term for price leads to an improved model fit, but the entry of fisheries appeared to decline at very high levels of price, indicating first diminishing returns, followed by decreasing returns to serial depletion. One explanation for the diminishing returns would be that, at any point in time, there is a limit on the number of possible new entrant global sea cucumber fisheries; despite increases in value providing incentives for the opening of new fisheries, there may be logistical and other cost-related barriers to the opening up of new sea cucumber fisheries. When considering the mean distance from Hong Kong as a measure of serial exploitation, there is also a natural limit within the geographic confines of the planet. 
Table 2. Summary of coefficients and overall model results. *** indicates significance less than or equal to 0.01 . Standard errors are reported in parentheses below the value for each coefficient. Blank cells indicate where coefficients were not incorporated into a given model (MT: metric ton).

\begin{tabular}{|c|c|c|c|c|c|c|c|c|}
\hline Model: & $1 \mathrm{a}$ & $1 b$ & $2 \mathrm{a}$ & $2 b$ & $3 \mathrm{a}$ & $3 b$ & $4 \mathrm{a}$ & $4 \mathrm{~b}$ \\
\hline Mean value per MT & $\begin{array}{c}3.903 \mathrm{E}-02 * * * \\
(4.520 \mathrm{E}-02)\end{array}$ & $\begin{array}{c}5.435 \mathrm{E}+00 * * * \\
(7.642 \mathrm{E}-01)\end{array}$ & & & $\begin{array}{c}9.808 \mathrm{E}-03 * * * \\
(2.078 \mathrm{E}-03)\end{array}$ & $\begin{array}{c}6.821 \mathrm{E}-01 \\
(4.396 \mathrm{E}-01)\end{array}$ & & \\
\hline Square of mean value per MT & $\begin{array}{c}-1.288 \mathrm{E}-05 * * * \\
(1.867 \mathrm{E}-06)\end{array}$ & $\begin{array}{c}-1.624 \mathrm{E}-03 * * * \\
(3.156 \mathrm{E}-04)\end{array}$ & & & $\begin{array}{c}-4.672 \mathrm{E}-06 * * * \\
(7.517 \mathrm{E}-07)\end{array}$ & $\begin{array}{c}-2.887 \mathrm{E}-04 \\
(1.590 \mathrm{E}-04)\end{array}$ & & \\
\hline $\begin{array}{l}\text { Mean value per MT of previous } \\
\text { year }\end{array}$ & & & $\begin{array}{c}4.000 \mathrm{E}-02 * * * \\
(4.778 \mathrm{E}-03)\end{array}$ & $\begin{array}{l}5.548 \mathrm{E}+00 * * * \\
(8.307 \mathrm{E}-07)\end{array}$ & & & $\begin{array}{c}1.041 \mathrm{E}-02 * * * \\
(2.240 \mathrm{E}-03)\end{array}$ & $\begin{array}{c}5.443 \mathrm{E}-01 \\
(4.558 \mathrm{E}-01)\end{array}$ \\
\hline $\begin{array}{l}\text { Square of mean value per MT of } \\
\text { previous year }\end{array}$ & & & $\begin{array}{l}-1.345 \mathrm{E}-05 * * * \\
(2.034 \mathrm{E}-06)\end{array}$ & $\begin{array}{l}-1.694 \mathrm{E}-03 * * * \\
(3.536 \mathrm{E}-04)\end{array}$ & & & $\begin{array}{l}-5.013 \mathrm{E}-01 * * * \\
(8.364 \mathrm{E}-07)\end{array}$ & $\begin{array}{l}-2.673 \mathrm{E}-04 \\
(1.702 \mathrm{E}-04)\end{array}$ \\
\hline Year & & & & & $\begin{array}{c}2.294 \mathrm{E}-01 * * * \\
(1.073 \mathrm{E}-02)\end{array}$ & $\begin{array}{c}3.729 \mathrm{E}+01 * * * \\
(2.271 \mathrm{E}+00)\end{array}$ & $\begin{array}{c}2.281 \mathrm{E}-01 * * * \\
(1.117 \mathrm{E}-02)\end{array}$ & $\begin{array}{c}3.858 \mathrm{E}+01 * * * \\
(2.272 \mathrm{E}+00)\end{array}$ \\
\hline Adjusted $R^{2}$ & 0.6872 & 0.6873 & 0.6796 & 0.6599 & 0.9625 & 0.9414 & 0.959 & 0.9404 \\
\hline$p$ value for model $F$ statistic & $<2.2 \mathrm{E}-16 * * *$ & $<2.2 \mathrm{E}-16 * * *$ & $3.125 \mathrm{E}-16 * * *$ & $1.942 \mathrm{E}-15 * * *$ & $<2.2 \mathrm{E}-16 * * *$ & $<2.2 \mathrm{E}-16^{* * *}$ & $<2.2 \mathrm{E}-16^{* * *}$ & $<2.2 \mathrm{E}-16^{* * *}$ \\
\hline Residual standard error & 2.451 & 414.4 & 2.465 & 428.6 & 0.8482 & 179.4 & 0.8814 & 179.3 \\
\hline Degrees of freedom & 62 & 62 & 61 & 61 & 61 & 61 & 60 & 60 \\
\hline
\end{tabular}

Fig. 4. Increasing trends in the measures of serial exploitation.
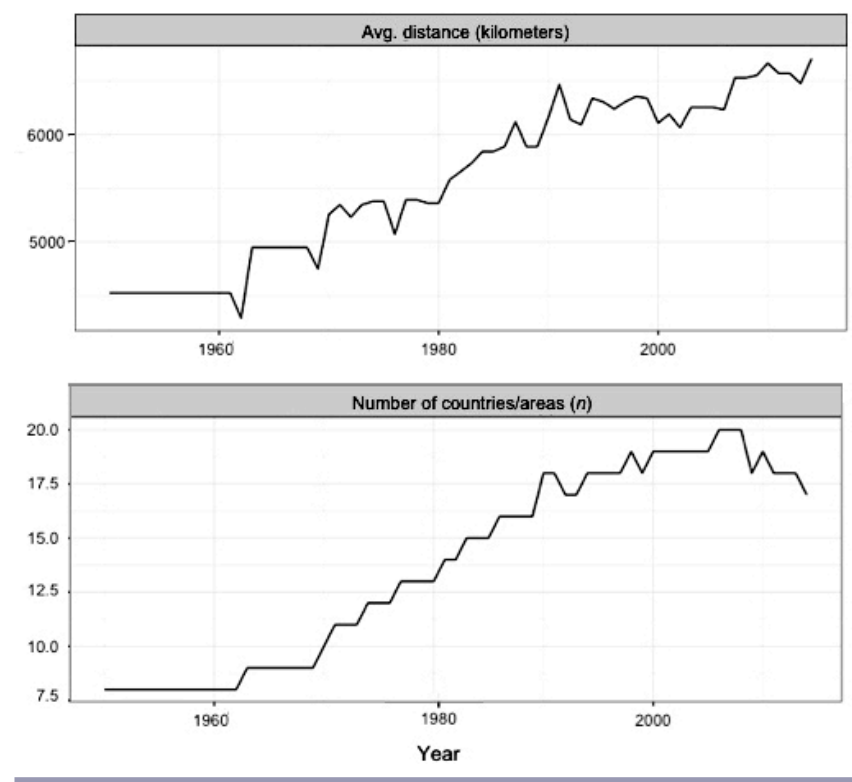

Our measures of serial depletion did not capture the entire picture of the global sea cucumber trade. Our two measures, as well as our visual summary of expanding fishery start dates, did not incorporate closures of sea cucumber fisheries. Do depleted fisheries keep producing sea cucumbers for trade through the whole time series? Or do they run out of resources and halt trade? Our models cannot answer these questions. A potential improvement on the mean distance measure of serial depletion may be to quantify the mean travel time of sea cucumber products from origin markets to a primary destination market such as Hong Kong. Incorporating the costs of transportation would provide a more detailed picture of market mechanics.

Despite the improvements of the SAUP data set over other data sources such as the UN Food and Agriculture Organization fisheries export data, our data most likely did not capture the entire extent of global sea cucumber trade (Pauly and Zeller 2015). Many countries or areas report sea cucumber catch as a collective catch of "other invertebrates" or "echinoderms" rather than as a distinct product class (Toral-Granda et al. 2008). Further, we were unable to locate catch data from all countries included in the start date data set from Anderson et al. 2010.

\section{Management issues}

Nonetheless, by improving our understanding of what drives the serial exploitation of sea cucumbers through these models, we may be able to identify management tools that could offer solutions to serial depletion. Further, advances in knowledge about sea cucumber species biology could increase the usefulness of bio-economic models, such as the one developed by Conrad et al. (2006) for the Galapagos sea cucumber fishery, for guiding local management and policy decisions. Some potential approaches to slowing or disrupting the pattern of serial exploitation include encouraging management practices that maximize local economic outcomes, developing global cooperation within sea cucumber conservation approaches, and exploring the potential of demand-side controls such as green labeling for sea cucumber products.

Given our simplified theoretical trade model, we can look at how implementing local management of no-take of sea cucumbers in a local fishery could still lead to the acceleration of the pace of new entry into the international sea cucumber trade. Considering the scenario in Fig. 1, if Origin Market 1 were to implement a policy of no-take of sea cucumber products prior to the development of a fishery that exports to the world market, this would effectively create a situation of reduced supply to the market similar to the situation where the Origin Market's sea cucumber stocks had been depleted. One difference is that such management would preclude any delay in the reduction of supply that occurs as a fishery undergoes its own depletion. This observation suggests that there may be a need for the world's fisheries to align their management on a global scale, even for fisheries within exclusive economic zones.

One place to begin such a global cooperation could be the listing of sea cucumber species with the Convention on International Trade in Endangered Species of Wild Fauna and Flora (CITES). As discussed by Bruckner et al. (2003), however, official listing would necessitate further scientific advances in the understanding of sea cucumber taxonomy and biology, as well as the post- 
processing identification of species characteristics. In addition to global cooperation, if individual fisheries (at national or regional levels) were to manage sea cucumber stocks to maximize economic outcomes, it could help ensure the sustainability of both the socioeconomic systems that rely on sea cucumber fisheries and the relevant sea cucumber stocks.

The development of a system of eco-labeling (green labels) for sea cucumber products comprises a potential "demand-side" approach to management. Green labels communicate unobservable information about the sustainability of a product to consumers. They aim to create market-based incentives that encourage producers to provide environmentally friendly goods (Reczkova et al. 2013). This form of management could take some time to develop, as Asian consumers at present may be unwilling to pay a premium for consumption on the basis merely of sustainable production. Further, it is not obvious how the sustainability of wild-harvest sea cucumbers would be ensured without some method of ensuring effective local management. Potentially, the emerging interest in the marine aquaculture of sea cucumbers could be a place to start with eco-labeling. In theory, such "farm-raised" sea cucumbers would displace supplies from wild stocks, thereby helping mitigate serial depletion.

\section{CONCLUSION}

The ex-vessel price of sea cucumber products drives the serial exploitation and consequent depletion of sea cucumbers, which adversely affects local marine environments on a worldwide scale. Thus, serial depletion is the consequence of patterns of international trade arising in the Anthropocene, which makes it an archetypal example of human modifications of the environment at levels that are clearly unsustainable. Potential policy solutions to this widespread problem can be identified, but practical implementation issues make the problem of the serial depletion of sea cucumber fisheries one that appears likely to become irrevocable without enduring shifts in consumer preferences for sustainable seafood.

Responses to this article can be read online at: http://www.ecologyandsociety.org/issues/responses. php/11150

\section{LITERATURE CITED}

Anderson, S. C., J. M. Flemming, R. Watson, and H. K. Lotze. 2010. Serial exploitation of global sea cucumber fisheries. Fish and Fisheries 12:317-339. https://doi.org/10.1111/j.1467-2979.2010.00397. $\underline{\mathrm{X}}$

Anderson, S. C., J. M. Flemming, R. Watson, and H. K. Lotze. 2011. Rapid global expansion of invertebrate fisheries: trends, drivers, and ecosystem effects. PLOS ONE 6(3):e14735. https:// doi.org/10.1371/journal.pone.0014735

Armstrong, J., D. Armstrong, and R. Hilborn. 1998. Crustacean resources are vulnerable to serial depletion - the multifaceted decline of crab and shrimp fisheries in the Greater Gulf of Alaska. Reviews in Fish Biology and Fisheries 8:117-176. https://doi. org/10.1023/A:1008891412756
Berkes, F., T. P. Hughes, R. S. Steneck, J. A. Wilson, D. R. Bellwood, B. Crona, et al. 2006. Globalization, roving bandits, and marine resources. Science 311:1557-1558. https://doi. org/10.1126/science. 1122804

Bordbar, S., F. Anwar, and N. Saari. 2011. High-value components and bioactives from sea cucumbers for functional foods-a review. Marine Drugs 9:1761-1805. https://doi. org/10.3390/md9101761

Bruckner, A. W., K. A. Johnson, and J. D. Field. 2003. Conservation strategies for sea cucumbers: Can a CITES Appendix II listing promote sustainable international trade? SPC Beche-de-mer Information Bulletin 18:24-33.

Bureau of Labor Statistics (BLS). 2017. Consumer price index. https://www.bls.gov/cpi

Conand, C., S. Shea, and A. To. 2014. Beche-de-mer trade statistics for Honk Kong in 2012. Beche-de-mer Information Bulletin 34:43-46.

Conrad, J., H. Franklin, L. Nøstbakken, S. Stone, and C. Viteri. 2006. Fisheries management in the Galapagos marine reserve: a bioeconomic perspective. Economic and Sector Study Series. Inter-American Development Bank.

Eriksson, H., and M. Byrne. 2015. The sea cucumber fishery in Australia's Great Barrier Reef Marine Park follows global patterns of serial exploitation. Fish and Fisheries 16:329-341.

Fabinyi, M. 2011. Historical, cultural and social perspectives on luxury seafood consumption in China. Environmental Conservation 39(1):83-92. https://doi.org/10.1017/S0376892911000609

Food and Agriculture Organization (FAO). 2016. The state of world fisheries and aquaculture. Topics Fact Sheets. Fisheries and Aquaculture Department. Rome, Italy.

Kahle, D., and H. Wickham. 2013. ggmap: spatial visualization with ggplot2. R Journal 5(1):144-161. http://journal.r-project.org/ archive/2013-1/kahle-wickham.pdf https://doi.org/10.32614/RJ-2013-014

Karpov, K. A., P. L. Haaker, J. K. Taniguchi, and L. RogersBennett. 2000. Serial depletion and the collapse of the California abalone (Haliotis spp.) fishery. Pages 11-24 in A. Campbell, editor. Workshop on rebuilding abalone stocks in British Columbia. NRC Research Press, Ottawa, Ontario, Canada.

Maine Department of Marine Resources (DMR). 2017. Historical Maine fisheries landings data. http://www.maine.gov/ dmr/commercial-fishing/landings/historical-data.html

Pacific Fisheries Information Network (PacFIN). 2017. Pacific States Marine Fisheries Commission, Portland, Oregon, USA. https://www.psmfc.org/

Pauly, D., V. Christensen, S. Guenette, T. J. Pitcher, U. R. Sumaila, C. J. Walters, et al. 2002. Towards sustainability in world fisheries. Nature 418:689-695.

Pauly, D., and D. Zeller (editors). 2015. Sea around us concepts, design and data (seaaroundus.org).

Purcell, S. W., C. Conand, S. Uthicke, and M. Byrne. $2016 a$. Ecological roles of exploited sea cucumbers. Oceanography and Marine Biology: An Annual Review 54:367-386. 
Purcell, S. W., P. Ngaluafe, S. J. Foale, N. Cocks, B. R. Cullis, and W. Lalavanua. 2016 $b$. Multiple factors affect socioeconomics and wellbeing of artisanal sea cucumber fishers. PLoS ONE https:// doi.org/10.1371/journal.pone.0165633

Reczkova, L., J. Sulaiman, and Z. Bahari. 2013. Some issues of consumer preferences for eco-labeled fish to promote sustainable marine capture fisheries in peninsular Malaysia. Procedia-Social and Behavioral Sciences 91:497-505. https://doi.org/10.1016/j. sbspro.2013.08.447

Srinivasan, U. T., R. Watson, and U. R. Sumaila. 2012. Global fisheries losses at the exclusive economic zone level, 1950 to present. Marine Policy 36:544-549. https://doi.org/10.1016/j. marpol.2011.10.001

To, A., and S. Shea. 2012. Patterns and dynamics of bêche-demer trade in Hong Kong and mainland China. TRAFFIC Bulletin 24(2):65-76.

Toral-Granda, V., A. Lovatelli, and M. Vasconcellos, editors. 2008. Sea cucumbers. A global review of fisheries and trade. FAO Fisheries and Aquaculture Technical Paper No. 516. Food and Agriculture Organization of the United Nations, Rome, Italy. 